Article

\title{
MAG welding of S700MC steel used in transport means with the operation of low arc welding method
}

\author{
Abilio Silva' ${ }^{1}$ Bożena Szczucka-Lasota ${ }^{2}$, Tomasz Węgrzynn ${ }^{2, *}$ and Adam Jurek ${ }^{3}$ \\ 1 University Da Beira Interior, Covilha, Portugal; \\ Prof. Abilio Silva; abilio@ubi.pt \\ 2 Silesian University of Technology, Poland; \\ Dr hab. inż. Bożena Szczucka-Lasota, prof. PŚl; Bozena.Szczucka-Lasota@polsl.pl \\ 3 Novar Sp. z o. o. Gliwice, Poland \\ * Correspondence: Prof. dr hab. inż. Tomasz Węgrzyn; Tomasz.Wegrzyn@polsl.pl
}

Received: 02.02.2019; Accepted: 05.03.2019

\begin{abstract}
Manufacturers of welding equipment strive to develop the most efficient, cost-effective and easy to process welding methods. This necessity is also related to welding of new, often hard-to-weld steel types. The article aims to present the possibility of welding a high-strength S700MC steel with an increased yield point using MAG (135) process and a blowtorch with an intelligent arc control. The blowtorch allows to reduce input energy and reduce splinters while maintaining the mechanical properties of the material. The S700MC steel has been selected for the tests purposefully, as it may create welding problems in order to maintain high strength and increased yield point. The applied technology provided lower power consumption compared to traditional welding machines and joints with very good mechanical properties were achieved.
\end{abstract}

Keywords: civil engineering; transport; mechanical resistance; S700MC welding; low arc energy; martensite; butt joints

\section{Introduction}

In civil engineering and in the construction of transport means, high-strength steels and steels with an increased yield point are increasingly being used [1]. Welding with a consumable electrode in the gas shield has been dominating among all types of arc welding for many years due to the wide range of applications and high efficiency [2]. The shield gases used for this method are divided into neutral (Metal Inert Gas) among those most often used is helium and argon or active (Metal Active Gas), i.e. carbon dioxide, or its mixture with argon [3,4].

By welding with MIG/MAG technology, almost all metals and alloys can be combined by appropriately selecting the electrode wires and shielding gases suitable for different materials. The MIG/MAG method is used in combining non-alloy and high-alloy structural steels, aluminium and its alloys, magnesium and its alloys, nickel and copper as well as alloys of these metals [5]. The demand for joints with high quality steel materials and heat-sensitive elements is constantly increasing, so there is a need to develop another, low-energy variants of arc welding in the gas shield [6 $\div 8]$. An important aspect of introducing low energy welding with the use of consumable electrodes to industrial practice is a significant reduction of dust and gas emissions to the working environment. The development of innovative processes will continue to progress as it is a natural sign of technical progress. Modern processes limit the significant

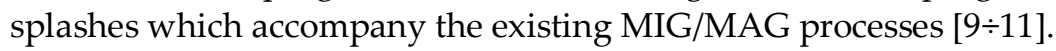

The article aims to check the possibility of welding a steel with an increased yield strength using the MIG/MAG process with understated arc energy. The tests were performed on the example of S700MC steel (steel increasingly used in civil engineering and in the construction of transport means due to its high yield strength at $700 \mathrm{MPa}$ ).

\section{Materials and methods}

Welded joints were made by MAG welding (135) using the Migatronic MIG-A Twist burner with intelligent arc control function. The burner is equipped with the IAC ${ }^{\mathrm{TM}}$ Intelligent Arc Control function, 
which provides a lower value of input energy, less distortion, splinters and machining, while maintaining the mechanical properties of the material. The used technology ensures much lower power consumption compared to traditional welding machines [12].

Butt test plates were used for testing in accordance with EN ISO 15614-1:

- sample P3 - butt joint (BW), steel S700MC, material thickness $3 \mathrm{~mm}$, welding method 135, flat welding position (PA),

- sample P2 - butt joint (BW), steel S700MC, material thickness $2 \mathrm{~mm}$, welding method 135, flat welding position (PA).

Welding tests were performed with an additional material EN ISO 16834-A G69 6M Mn4N1.5CrMo, in the gas shielding mixture M21 $\left(82 \% \mathrm{Ar}+18 \% \mathrm{CO}_{2}\right)$ with the assumed gas flow of $13 \mathrm{l} / \mathrm{min}$. Material transfer method - globular arc. The input energy during the welding of thicker sheets $(3 \mathrm{~mm})$ was 4.3 $\mathrm{kJ} / \mathrm{cm}$. The input energy during the welding of thinner sheets $(2 \mathrm{~mm})$ was $3.3 \mathrm{~kJ} / \mathrm{cm}$.

The S700 MC steel was used for the tests, which due to the low carbon content can be welded using various processes. All welding tests were carried out without preheating. Tables I and II show the chemical composition and mechanical properties used in the S700 MC steel tests.

Table I. Chemical composition of S700MC steel [13]

\begin{tabular}{ccccccccc}
\hline $\mathbf{C} \%$ & $\mathbf{S i} \%$ & $\mathbf{M n} \%$ & $\mathbf{P} \%$ & $\mathbf{S} \%$ & $\mathbf{A l} \%$ & $\mathbf{N b} \%$ & $\mathbf{V} \%$ & $\mathbf{T i} \%$ \\
\hline 0,12 & 0,10 & 2,10 & 0,025 & 0,010 & 0,015 & $0,09 *$ & $0,20^{*}$ & $0,15^{1}$ \\
$\mathrm{C} \%$ & $\mathrm{Si} \%$ & $\mathrm{Mn} \%$ & $\mathrm{P} \%$ & $\mathrm{~S} \%$ & $\mathrm{Al} \%$ & $\mathrm{Nb} \%$ & $\mathrm{~V} \%$ & $\mathrm{Ti} \%$ \\
\hline
\end{tabular}

${ }^{1}$ sum of $\mathrm{Nb}, \mathrm{V}$ and Ti content $=0.22 \% \max$

Table II. Mechanical properties of S700MC steel [13]

\begin{tabular}{|c|c|c|c|}
\hline Yield stress $^{1}$ & $\begin{array}{l}\text { Ultimate tensile } \\
\text { strength }\end{array}$ & \multicolumn{2}{|c|}{ Ultimate elongation of the sample with a thickness of } \\
\hline $\begin{array}{c}\text { YS N/mm } \\
\text { min }\end{array}$ & $\begin{array}{c}\text { UTS N/mm } \\
\text { min } \div \max \end{array}$ & $\begin{array}{c}<3 \mathrm{~mm} \\
\mathrm{~A} 80 \% \mathrm{~min}\end{array}$ & $\begin{array}{c}\geq 3 \mathrm{~mm} \\
\mathrm{~A}_{5} \% \mathrm{~min}\end{array}$ \\
\hline $500 \div 700$ & $750 \div 950$ & 10 & 12 \\
\hline
\end{tabular}

${ }^{1}$ for a thickness $>8 \mathrm{~mm}$, the minimum value of the yield stress may be lower by $20 \mathrm{MPa}$

A butt welded joint made of S700MC steel with a thickness of $3 \mathrm{~mm}$ and $2 \mathrm{~mm}$ (samples P2, P3) was made. The MAG welding method (135) was used in the flat position (PA) in accordance with the requirments of EN 15614-1. The preparation of material for a single-bead welding is shown in Figure 1, and the method of making the joint is shown in Figure 2.

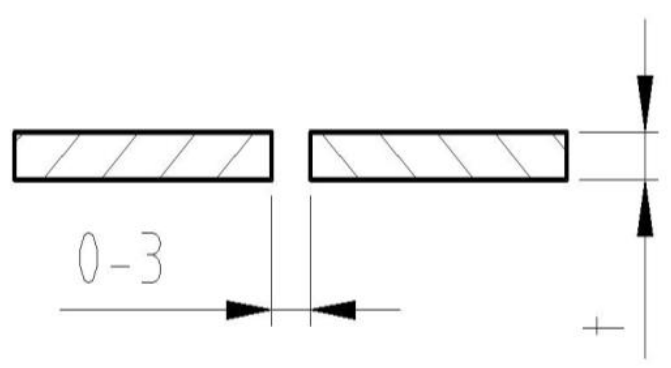

Fig. 1. Groove shape for both samples tested (P2, P3)

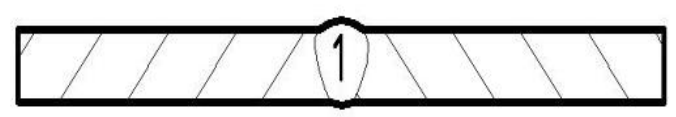

Fig. 2. One-stitch welding manner (samples P2, P3)

The detailed data of the welding process parameters for sheets with a thickness of $3 \mathrm{~mm}$ are given in Table III, and sheets with a thickness of $2 \mathrm{~mm}$ in Table IV. 
Table III. P3 sample welding details

\begin{tabular}{cccccccc}
\hline $\begin{array}{c}\text { Layers } \\
\text { order }\end{array}$ & $\begin{array}{c}\text { Welding } \\
\text { method }\end{array}$ & $\begin{array}{c}\text { Diameter of the } \\
\text { electrode, mm }\end{array}$ & $\begin{array}{c}\text { Current } \\
\text { intensity, A }\end{array}$ & $\begin{array}{c}\text { Voltage, } \\
\text { V }\end{array}$ & $\begin{array}{c}\text { Polarizatio } \\
\mathbf{n}\end{array}$ & $\begin{array}{c}\text { Welding } \\
\text { speed, } \\
\mathbf{m m} / \mathbf{m i n}\end{array}$ & $\begin{array}{c}\text { Input } \\
\text { energy, } \\
\mathbf{k J} / \mathbf{m m}\end{array}$ \\
\hline 1 & 135 & 1,0 & 100 & 19 & DC ",+ & 200 & 0,43 \\
\hline
\end{tabular}

Table IV. P2 sample welding details

\begin{tabular}{cccccccc}
\hline $\begin{array}{c}\text { Layers } \\
\text { order }\end{array}$ & $\begin{array}{c}\text { Welding } \\
\text { method }\end{array}$ & $\begin{array}{c}\text { Diameter of the } \\
\text { electrode, mm }\end{array}$ & $\begin{array}{c}\text { Current } \\
\text { intensity, A }\end{array}$ & $\begin{array}{c}\text { Voltage, } \\
\text { V }\end{array}$ & $\begin{array}{c}\text { Polarizatio } \\
\mathbf{n}\end{array}$ & $\begin{array}{c}\text { Welding } \\
\text { speed, } \\
\mathbf{m m} / \mathbf{m i n}\end{array}$ & $\begin{array}{c}\text { Input } \\
\text { energy, } \\
\mathbf{k J} / \mathbf{m m}\end{array}$ \\
\hline 1 & 135 & 1,0 & 90 & 19 & $\mathrm{DC}_{\text {, }}++^{\prime \prime}$ & 200 & 0,33 \\
\hline
\end{tabular}

\section{Methods, scope of the research}

The scope of research included non-destructive testing (NDT):

- Visual testing (VT) of the made welded joints was performed with an eye armed with a loupe at $3 \times$ magnification - tests were carried out in accordance with the requirements of the PN-EN ISO 17638 standard, evaluation criteria according to the EN ISO 5817;

- Magnetic-particle testing (MT) - the tests were carried out in accordance with the PN-EN ISO 17638 standard, the evaluation of the tests was carried out in accordance with the EN ISO 5817 standard, the device for testing was a magnetic flaw detector of REM - 230 type.

The destructive tests included:

- Visual tests on microsections of welded joints were performed with an eye armed with a loupe at $3 \times$ magnification - tests were performed according to PN-EN ISO 17638 with reagents for testing according to PN-CR 12361 standard, evaluation criteria according to EN ISO 5817;

- The bending test was carried out in accordance with the PN-EN ISO 5173 standard, using a ZD-40 testing machine;

- Examination of microstructure of specimens digested with Adler reagent using light microscopy (LM).

\section{Results}

\section{The results of non-destructive tests}

Visual testing of panels with a thickness of $3 \mathrm{~mm}$ and $2 \mathrm{~mm}$ (P2 and P3) was made using standard auxiliary measures, i.e. $x 3$ loupe, luxmeter with white light $520 \mathrm{Lx}$. It was found that the welds were made correctly and met the quality requirements, they were characterized by the limit of acceptability "B" according to PN-EN ISO 5817. Magnetic-particle test for sheets with a thickness of $3 \mathrm{~mm}$ and $2 \mathrm{~mm}$ (P2 and P3) was made using the wet method with the following conditions: field strength $3 \mathrm{kA} / \mathrm{m}$, white light $515 \mathrm{Lx}$, temperature $20^{\circ} \mathrm{C}$, MR-76 detection means, MR-72 contrast. Magnetic-particle test results are presented in Table V.

Table V. Results of the magnetic-powder tests of P3 and P2

\begin{tabular}{cccc}
\hline Designation & Tested element & Detected indications & Findings \\
\hline P3 & joint BW; $l=500$ & unacceptable surface indications were not found & positive \\
P2 & joint BW; $l=400$ & unacceptable surface indications were not found & positive \\
\hline
\end{tabular}

\section{The results of destructive tests}

A static tensile test of 2 and $3 \mathrm{~mm}$, butt joints was carried out at $20^{\circ} \mathrm{C}$ on a ZD-100 testing machine. Three tensile tests were carried out, the samples were designated: P2a, P2b, P2c and P3a, P3b, P3c, respectively. The test results for a $3 \mathrm{~mm}$ thick specimen are shown in Table VI, for a $2 \mathrm{~mm}$ thick sample in Table VII. Analysing the data from tables VI and VII it can be seen that the joints were made correctly, 
and the yield stress (YS) and ultimate tensile strength (UTS) are at the required high level. For the yield point, the requirement is min. $700 \mathrm{MPa}$, and the strength limit should be within $750 \div 950 \mathrm{MPa}$ according to EN ISO 15614-1. In the obtained measurements, YS was in the range of 760 $\div 792 \mathrm{MPa}$, while UTS was between $795 \div 812 \mathrm{MPa}$. Relative elongation $(\varepsilon 5)$ in both cases is at an acceptable level.

Table VI. The results of elongating tests of P3 sheet

\begin{tabular}{cccc}
\hline Sample & Sample P3a & Sample P3b & Sample P3c \\
\hline $\mathrm{a}[\mathrm{mm}]$ & 3,05 & 3,05 & 3,05 \\
$\mathrm{~b}[\mathrm{~mm}]$ & 25,04 & 25,37 & 25,18 \\
YS [MPa] & 792 & 762 & 781 \\
UTS [MPa] & 812 & 782 & 795 \\
$\varepsilon 5[\%]$ & 9,1 & 8,1 & 8,3 \\
\hline
\end{tabular}

Table VII. The results of elongating tests of P2 sheet

\begin{tabular}{cccc}
\hline Sample & Sample P2a & Sample P2b & Sample P2c \\
\hline $\mathrm{a}[\mathrm{mm}]$ & 2,02 & 2,02 & 2,02 \\
$\mathrm{~b}[\mathrm{~mm}]$ & 25,03 & 25,24 & 25,08 \\
YS [MPa] & 760 & 772 & 771 \\
UTS [MPa] & 798 & 802 & 797 \\
$\varepsilon 5[\%]$ & 8,5 & 8,7 & 8,2 \\
\hline
\end{tabular}

Then a bending test was carried out. The tests used: sample with a thickness of $a=3 \mathrm{~mm}$, width of the sample $b=20 \mathrm{~mm}$, mandrel $d=22 \mathrm{~mm}$, spacing of supports $d+3 a=31 \mathrm{~mm}$ and the required angle of bending $180^{\circ}$. For samples with a thickness of $2 \mathrm{~mm}$, the parameters were similar: width of the sample $b=20$ $\mathrm{mm}$, mandrel $\mathrm{d}=14 \mathrm{~mm}$, spacing of supports $\mathrm{d}+3 \mathrm{a}=31 \mathrm{~mm}$ and the required angle of bending $180^{\circ}$. Five bending test measurements were carried out for each tested joint thickness on the root side (P3G and P2G) and on the face side (P3L and P2L samples). The test results are summarized in Table VIII.

From the analysis of the results presented in Table VIII, it follows that the test was carried out correctly, the evaluation of the tests is positive, because no cracks and other disconformities were found in the samples tested.

Table VIII. Bending test results of P3

\begin{tabular}{ccccc}
\hline $\begin{array}{c}\text { Sample } \\
\text { designation }\end{array}$ & Deformed side & ao $\mathbf{x} \mathbf{b}_{\mathbf{0}}[\mathbf{m m}]$ & Bending angle $\left[^{\circ}\right]$ & Notes \\
\hline P3G & root of weld & $3,0 \times 20,0$ & 180 & no cracks, no disconformities \\
P3L & face of weld & $3,0 \times 20,0$ & 180 & no cracks, no disconformities \\
P2G & root of weld & $2,0 \times 20,0$ & 180 & no cracks, no disconformities \\
P2L & face of weld & $2,0 \times 20,0$ & 180 & no cracks, no disconformities \\
\hline
\end{tabular}

\section{Metallographic examination}

Metallographic examinations were made and the structures of $3 \mathrm{~mm}$ (sample P3) and $2 \mathrm{~mm}$ (sample P2) thick joints were checked. Observations of the samples digested in Adler's reagent were carried out on the Reichert light microscope. The examined joints are dominated by a martensitic and ferritic structure - Figure 3 shows the structure of the P3 sample. 


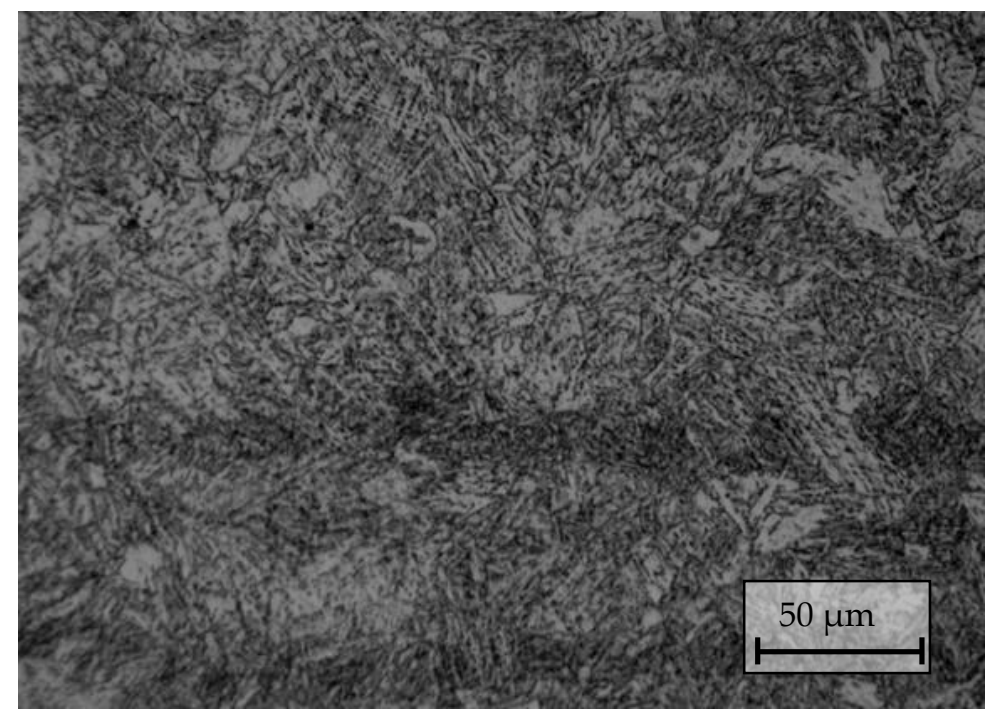

Fig. 3. Structure of the joint (sample P3), visible martensite and fine-grained ferrite (LM)

\section{Summary}

The use of low-energy methods, ColdArc, CMT and STT is an excellent alternative to traditional welding or MIG/MAG brazing of thin sheets of non-alloy and other steels. The main advantages of using these methods are primarily the limitation of spraying and welding deformations, which significantly improves the aesthetics of joints, as well as increasing welding performance, by increasing the speed of the process and reducing or eliminating the time needed for cleaning and straightening of the joints.

To confirm the proposed method, it was decided to carry out non-destructive tests, static tensile test, bending test and microstructure investigation of the obtained welded joints. The S700MC steel with increased strength with a yield point of $700 \mathrm{MPa}$ was selected for the tests, for which it is difficult to ensure high Re requirements after welding. The tests confirmed that MAG welding with low arc energy resulted

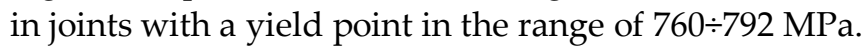

The results of all the tests presented in the article were positive, which confirms that the selected welding parameters proposed by the low arc welding method are correct. The quality of joints according to PN-EN ISO 5817 has been assessed in class B.

The low arc welding method is a further variant of the MIG/MAG process, based on interference in the current and arc voltage during short-arc welding.

The test results indicate that the proposed new low arc welding method is a prospective process for use in the production of thin-walled structural elements.

\section{References}

1. Agrawal K.C. Industrial Power Engineering and Applications Handbook, 1st ed.; Elsevier Inc: 2001.

2. Szymański G.; Patecki A. Eddy current and temperature of the sheath in tree-phase pipe sheathing system, IEEB Transaction of magnetics, (2004-2006), Vol. 20(5), 2004-2006. [CrossRef]

3. IEEE Standard for Metal-Enclosed Bus. In IEEE Std C37.23-2015 (Revision of IEEE Std C37.23-2003), IEEE. [CrossRef]

4. Skowrońska B.; Szulc J.; Chmielewski T.; Golański D. Wybrane właściwości złączy spawanych stali S700 MC wykonanych metodą hybrydową plazma + MAG. Welding Technology Review, 2017, Vol. 89(10), 104-111 [CrossRef]

5. Golański D.; Chmielewski T.; Skowrońska B.; Rochalski D. Advanced Applications of Microplasma Welding. Biuletyn Instytutu Spawalnictwa w Gliwicach, 2018, Vol. 62(5), pp. 53-63, DOI: 10.17729/ebis.2018.5/5. [CrossRef]

6. Jaeschke B.; Węglowski M.; Chmielewski T. Current State and Development Opportunities of Dynamic Power Source for GMA Welding Processes. Journal of Manufacturing Technologies, 2017, Vol. 42(1), 23-30. [Hyperlink]

7. Ferenc K.; Cegielski P.; Chmielewski T. Technika spawalnicza w praktyce: Poradnik inżyniera konstruktora i technologa, 1st ed.; Verlag Dashofer, Warszawa, Poland 2015. 
8. Izairi N.; Ajredini F.; Vevecka-Pfiftaj A.; Makreski P.; Ristova M.M. Microhardness evolution in relation to the cFigtalline microstructure of aluminum alloy AA3004. Archives of Metallurgy Materials, 2018, Vol. 63(3), 1101-1108, DOI: $10.24425 / 123782$ [CrossRef]

9. Giles T.L.; Oh-Ishi K.; Zhilyaev A.P.; Swami S.; Mahoney M.W.; McNelley T.R. The Effect of Friction Stir Processing on the Microstructure and Mechanical Properties of an Aluminum Lithium Alloy. Metallurgical and Materials Transactions, 2009, Vol. 40(1), 104-115. [CrossRef]

10. Hamilton C.; Dymek S.; Węglowska A.; Pietras A. Numerical simulations for bobbin tool friction stir welding of aluminum 6082-T. Archives of Metallurgy Materials, 2018, Vol. 63(3), 1115-1123. [CrossRef]

11.Szczucka-Lasota B.; Węgrzyn T.; Stanik Z.; Piwnik J.; Sidun P. Selected parameters of micro-jet cooling gases in hybrid spraying process. Archives of Metallurgy Materials, 2016, Vol. 61(3), 621-624. [CrossRef]

12. Benato R.; Dughiero F.; Forzan M.; Paolucci A. Proximity effect and magnetic field calculation in GIL and in isolated phase bus ducts. IEEE Transactions on Magnetics, 2002, Vol. 38(2), 781-784. [CrossRef]

13. SSAB, Products, Strenx $® 700 M C$ Plus, [Hyperlink]

(C) 2019 by the authors. Submitted for possible open access publication under the terms and conditions of the Creative Commons Attribution (CC BY) license (http://creativecommons.org/licenses/by/4.0/). 